\title{
Penal - Juridical Aspects of Violence within Family in Albania
}

\author{
Nikolin Hasani \\ Ph.D candidate at Faculty of Justice, \\ University of Tirana, Albania \\ hasani.nikolin@yahoo.com \\ Ph.D Alketa Elezi \\ University "Kristal", Albania \\ elezialketa@yahoo.com
}

Doi:10.5901/mjss.2013.v4n4p391

\section{Abstract}

\begin{abstract}
Parents in Albania, especially mothers exercise violence toward children during their adolescence as a protective measure to protect them from several viruses that have infected our society days. Life experiences and socio-psychological studies show that, especially boys, since childhood and during adolescence have been exposed to domestic violence exercised directly to them or to other members of the family. This conclusion is confirmed by the social geography of the black chronicle in the Albanian reality. According to the available data in the Statistical Office of the General Prosecutor of Albania Republic, about $41.1 \%$ of crimes such as murder, wounding, robbery with violence, kidnapping etc are committed by young people 19-26 years old age group and this percentage is increased a lot during the recent years. A study of family background of young people who have committed criminal acts with a high level of aggression against another's life shows that most of them are adults grown up and socialized in families where is exercised violence, where older males discuss about perverse behaviours, for crimes and violence against others. Violence within family is a global phenomenon and Albania, although a small country, cannot remain outside its negative impact. The aim of this paper is to present an overview of the violence within family in Albania, its forms and the factors that cause it.
\end{abstract}

Keywords: violence, family, children, punishment, parents.

\section{Introduction}

In the Fourth World Conference in Beijing ${ }^{1}$ held in September 1995, violence within family was defined as "a statewide problem and you must treat it as such". In the same conference it was emphasized that "violence against women constitutes a violation of human rights, as well as a barrier to the achievement of equality, development and peace".

In the Convention on the Elimination of all forms of discrimination against women is given a definition for violence within family as "a key mechanism by which women are forced to stay in the inferior position compared with men".

In the Declaration "Violence against women", made by the General Assembly of the United Nations, is given the first official definition, which states that "violence against women in the family would be considered as an act based on gender which results in or may result in: physical, sexual or psychological, or causing suffering to women, including threats of such acts, coercion or arbritar deprivation of liberty, whether these occurr in public or in the private life ".

Violence within family ${ }^{2}$ is a painful phenomenon, wrapped rarely with myths and uncertainties. It is a phenomenon which cannot be studied easily as it encompasses many aspects of private life and is influenced by factors of different nature. Violence within family is an important problem for all the countries. Every country has its way of determining and treatment of violence within family. Way that a society defines causes as violence within family depends on culture, economic status, religious, legal or geographic location in the country. Behaviors considered normal in a society, in another one may be illegal. Now the concept of violence within family includes all types of violence and abuse, not just

1 Conferene held in September 1995

2 Guidence of MPÇSSHB no.1220, date 27.5.2010 "For defining of evaluation and monitoring evaluation of gender equality and violence toward women, including violence within family, monitoring, gathering and compiling the data". Official bulletin of Albania Republic, 78. Tirana, Albania: Center for Public Publications. 
physical violence. Violence within family does not concern only the violence against one of the spouses, which in most cases is exercised towards women. The concept of violence within family today is included and understood violence against women, parental violence against children, violence among children, the violence of children, mostly teenagers to parents, as well as violence against the elderly.

Violence against women and violence against children has historically attracted the attention of researchers and experts of this field. Violence among children, violence against children and violence against the elderly parents have received little or no attention from researchers and experts. This does not mean that these forms of violence within family are less disturbing to the general public and that the latter has no interest to be informed about them. Now it is a reality that violence in the family, although a problem presented only in the middle of the last century (1960), has gone through a long process of definition and identification. Despite various forms of violence within family, actually the focus is shifted toward the violence against women and children within family.

\section{Causes of violence within family}

Some of the problems that were faced and continues to face the Albanian society are the sense of competition, greed for maximum profits in a shorter period of time, strengthen of indifference sense of to the community group, the dissolution of the group, family problem, withdrawal from school and accompany of this phenomenon with a significant decline of educational level and mass education, increased abuse of narcotic drugs, alcohol and tobacco, the problem of prostitution and trafficking. Meanwhile, the lack of social policies in favor of people in need, the lack of serious investment in education and health and lack of development projects in remote areas of mountainous or less likely to develop, have a significant impact on the speed and spread of violence phenomenon in the Albanian family. In this context, the economic, political and social development of the country, the Albanian school students continue to participate in the poorest groups of the population in the country.

Violence is quite complex phenomenon, which incorporate in itself some means of pressing social and historical development in our country. It is the result of not right relations within family and testifies serious discrimination in society and our family. But simultaneously, its level and severity are related with the patriarchal traditions of the family, area, etc., which provide the bed and outlook for social action, mystification and its justification as an exercise of authority, the right of family male to punish. More or less these features there is the exercise of violence in cities, where is interlaced indiference with material husband primacy, which ultimately rests on cultural differentiation and men prepotence who fail to understand harmony and understanding, as well as true values of contemporary families.

Written and electronic media reflects the presence of violence in our society. After the years $90 \mathrm{~s}$ it has been reported more and more news of crime violence. Firstly, the journalists addressed this phenomenon with shy, but gradually it has taken place quite visibly. In search of sensationalism they often violate the ethics and professionalism of conveying to the reader a negative message. Trying to evidentate the details of this crime, often through writing are not analyzed social reasons, the collision of cultures, but almost proverbial passion for considering the girl or woman as an object which can behave as you want. However, international and internal factor Albania has influenced in this area, which is reflected in meetings organized by state institutions and NGOs on a draft law on violence, war strategies against violence and for the extension of studies at the national level.

Violence within family ${ }^{3}$ is any form of physical, psychological, sexual and economic abuse that takes place between members of a family and intimate partners and as such undermines physical and spiritual well-being of individuals involved in it. In most cases, the violence exercised against women within the couple, parents on their children, among children, children to their parents and children to the elderly.

One of the challenges to be faced in the analysis of data on violence within family remains the difficulty of measuring the level and scale of it to the fact that this is a phenomenon that occurs mainly within the walls of the house that requires awareness not only of the victim to be mounted on the mentality and attitudes that keep him connected to the perpetrator and to denounce it, but that society should consider it as a problem for all society that should not be tolerated or justified.

${ }^{3}$ Law 9669, date 18.12.2006 "For taking actions against violence within family" Official notebook, No. 150, Page 6113. Tirana Albania: Center for Official Publications. 


\subsection{The factors that incite violence within family ${ }^{4}$}

Factors that affect violence within family are divided into macro-level factors, family-level factors and personal level factors.

Macro-level factors include: the influence of culture, economics, politics, major demographic movements etc.

Household or micro level factors include: family relationships, patterns that they are grown with, family education, ways of raising children etc.

Personal level factors may include: the individual's mental health problems, alcohol abuse, drugs, stress, education, various personality disorders, and personal experiences with family relations etc.

\section{Forms of violence and its conseguences}

\subsection{Forms of violence}

In all manuals, studies and reports are mentioned forms of violence such as the following: physical, psychological, sexual and economic.

\subsubsection{Physical violence}

Physical violence includes: pushing, hitting, scratching, pinching, biting, jumping, closing at home, hitting with various objects, threatening with a knife or other weapon, refusing to help the woman when she is pregnant or sick, etc., until murder.

Physical violence is a form of violence that victims are able to perceive better and accept the nature of the exercise and its visible trail that leaves it to the victim.

\subsubsection{Sexual violence}

Sexual violence includes: handling partner as a sexual object, the obligation to make striptease, the obligation to have sex, insistence to touch and to do whatever he wants, the obligation to have sex with someone else, performing sadistic sexual acts, coercion partner to have sex after physical abuse or as a condition to maintain their relationship, performing sex outside etc.

It is noted that spouses or partners who perform this kind of violence, they want to demonstrate their strength or ability to dominate and humiliate the victim.

\subsubsection{Psychological violence}

In the Albanian reality we have observed these forms of the emergence of psychological violence: ignoring feelings, constant criticism, continual contradiction of opinions, humiliation in public or in private, trying to convince that violence is deserved from their actions, partner threat of their spouse, persistent signs of jealousy, threats of taking the children, keeping money hidden, keeping at home without work, abuse of children, called degrading names etc.

\subsubsection{Economical violence}

Women are also faced with various forms of economic violence: partner control over financial family income or a prohibition of women participation in decisions about spending money, even refusal of money to cover the basic needs of the family, denial of ownership of the common property, etc.

${ }^{4}$ Guidence of Ministry of Labour and Social Affairs Services no.1220, date 27.5.2010 "For defining of evaluation and monitoring evaluation of gender equality and violence toward women, including violence within family, monitoring, gathering and compiling the data". 


\subsection{Consequences of violence}

\subsubsection{Consequences of violence on women ${ }^{5}$}

Based on the results of different studies about the violence within family, conseguences of violence on women are as follow:

Endangers life, health, psychological integrity and their freedom.

The most common violation of human rights, but also unaddressed.

It is a form of gender-based violence as derived from the low position of women in society.

Violence within family affects not only women, but also other categories such as elderly, disabled people or children.

\subsubsection{Consequences of violence on children}

Based on the results of different studies about the violence within family, conseguences of violence on women are as follow:

- Being witness damages the psychological and emotional state (aggression, fear, anxiety, depression, and feeling of guilt, headache, and difficulty at school).

- There is a direct connection between violence against women and violence against children: $50 \%$ of men who violate violate their wives and children. Battered mothers exert more violence against children.

- Children may suffer physical injuries during episodes of violence within family.

- Children are used by abusers to manipulate and raped the victim, either during the marriage or during the divorce.

\section{Gender relevance}

Equality policies usually target women in general - but mainstreaming should be able to make targeted diverse situations to different groups of women and men (migrated women, youth, elderly etc). Gender relevance put people at the center of policy - making and there are some reasons for this:

- Because it leads to a better governance.

- Because it includes both men and women and uses fully human resources.

- Because it makes visible gender equality in the society norm.

- Because it takes into considerfation the diversity among men and women.

\subsection{Gender facilitator conditions}

The most important prerequisite is the political will. Government - or higher authority (for example in the case of an organization, etc.) - will have to issue a mission statement, making it clear that the goal is to become a norm the gender perspective with the objective to achieve gender equality. Another prerequisite is to have a specific policy on gender equality.

Legal mainstreaming can not be fulfilled without the existence of a politics. So, countries or organizations wishing to start mainstreaming but do not have such policies, needs to compile them at the same time.

Other important conditions of mitigation are:

- The existence of statistics on the current situation of women and men (statistics compiled by sex). These are essential to convince policy makers.

- The existence of gender studies which generate knowledge about relations between the sexes; funds (often partial redistribution of funds), human resources (ie for the treatment of policy-makers), and the last but not at lees important, the full participation of women in political life and decision-making processes. Most supporters of equal gender relations between men and women are women. It is therefore important that they enter into the decision-making processes to ensure that the values, interests and vital experiences of different groups of women are taken into account when making decisions.

${ }^{5}$ Local strategy for implementing the Advices of EU for the violence against women and girls of all discrimination forms. 


\section{How to fight gender inequality? ${ }^{6}$}

Techniques and tools should be divided into three main groups:

\subsection{Techniques and analytical tools}

These are: statistics compiled by sex, questionnaires and expectations about gender relations, cost-benefit analysis from a gender perspective, and research in gender studies, which are the most important basis for gender mainstreaming. Other means of policy makers are: checklists (defining objectives, describe actions to be taken); guidance and reference topics - which are not accurate, but give more freedom to implement in practice mainstream the norms. Gender impact assessment is another tool that has originated from the environmental sector but is used for standardizing. It is a filtering of political proposal to assess the different impacts on women and men, and if their needs are taken into account equally. And finally involving monitoring reports and regular meetings is also a means of preparing new policies.

\subsection{Educational tools}

Educational tools contain two main aspects: awareness and knowledge transfer.

Awareness aims to make people more sensitive to gender issues and their discussion will help the actors normally involved in policy processes that reveal gender issues and develop policies that take into consideration gender. This can be done through: awareness and training courses - ranging from the highest levels of management, special experts who join the unit for some time ("mobility expert"); manuals (to be used during and after training); manuals and leaflets to the general public; educational material for use in schools.

\subsection{Participation in counseling.}

These are very important because they help expert for gender equality and other experts to work together. Examples are: mindset reservoirs, working and management groups (collaboration between departments and directorates); specific measures to insure women's participation in decision-making organs; conferences; senimares aimed at informing the public and those that have to do with politics; listening (to help people to take part in the policy-making process).

\subsection{Actors and their roles}

Legal mainstreaming means that all actors involved in the designing, implementation and evaluation of policies. Implementation of legal mainstreaming means that gender equality must be a concern of a large number of people. Some aspects of legal mainstreaming need to include specific actors, for example: researches need the participation of academic experts and decision includes politicians. There is also a role for external experts, NGOs, pressure and interests groups, as well as the media. The role of supervisional institutions is also an important support such as supportive, incentive and initiative factor.

\subsection{Politics}

When you prepare a political plan, the first step is to identify who will be responsible for the initiation of legal mainstreaming. Further steps are to equate real situation - preconditions that are met, the characteristics of the policymaking process and to develop a plan that takes into consideration this realistic situation? ${ }^{7}$. Finally, the last step is to monitor the results.

\section{Conclusions}

Often, children are vulnerable precisely where they need to be more protected, where they expect safety, love and

${ }^{6}$ Law No. 9970, date 24.7.2008 "For gender equality in society". Official notebook, No 125, Page 5540. Tirana, Albania: Center for official publication.

${ }^{7}$ Resolution "For combating violence on women and enhancing parliamentary dimension to combat domestic violence". Tiranë, Albania. 
support, just within family. Reality proves that family is the place where life of many of them is risked, is the place where they are despised, insulted, beaten, raped, and even killed. Violence within family is a global phenomenon and Albania, although a small country cannot remain outside its negative impact. As a Balcanic country, Albania has experienced Violence within family from inherited habits, written and unwritten rules of the country. In the case of our country, it is necessary to have in mind the powerful influence of cultures carried out by invaders coming from the East, with their customs and laws, which for centuries narrowed spaces by interrupting social development and contacts with the West. After World War II, during the years of socialism, the problem stayed in disguise, though sometimes acute.

Only after 1990s, press freedom and the creation of independent associations particularly for human rights and women protection, enabled the treatment of domestic violence causes as discriminatory occurrence. Albania is a country with a new democracy. During the transition period, it was involved in a series of democratic, institutional, legal, structural and administrative reforms that enabled the development of the country in a successful and irreversible way. In 1991, Albania entered the path of political and economic reforms aimed the creation of democratic system through the protection of human rights and increasing the standard of living. Extended transition has created very serious economic problem. Democratic system continues to be fragile, and state and local institutions are still weak. They lack basic resources, and the foundations for sustainable growth are still tentative.

From the confessions of women gathered in the framework of studies organized by specialist and foreign institutions in Albania, it results that abuse is a complex phenomenon and of different forms ranging from: humiliation, intimidation, social isolation, beating and sexual relations with violence. Physical violence starts from a buffet to the use of a weapon. Many women live in fear not only for their lives, but also the lives of their children and families. The experience of sexually abused women proves that violence is constant and varies from its nonphysical forms, humiliation, threats, verbal humiliation and pressure forcing them to have sex without their desire, beatings and rape. Physical violence is often accompanied by attempts to control women's social activity as well as their actions. Violence against women encompasses a wide variety of actions and behaviors, including verbal, physical and sexual abuse, but also the limitation of food, health care or economic means as well as other forms of violence that occur during the life stages .

Women of all cultures experience violence, but nonetheless are noticed several indicators, such as poverty and lack of education which are often accompanied by high levels of violence, experiences of violence are reported also by women of all educational levels and socio-economic social status. Norms and gender steorotipet society, economic dependency on men, lack of legislation or the implementation of existing legislation are often contributers to the existence of violence in marital relationships. Despite the difficulties and complexities of this phenomenon, we are faced with a situation that requires answers to questions such as: Which are the dimensions of the phenomenon of violence within family in Albania and what percentage of this violence is directed against women?

Parents in Albania, especially mothers exercise violence toward children during their adolescence as a protective measure to protect them from several viruses that have infected our society days.

Life experiences and socio-psychological studies show that, especially boys, since childhood and during adolescence have been exposed to domestic violence exercised directly to them or to other members of the family.

This conclusion is confirmed by the social geography of the black chronicle in the Albanian reality. According to the available data in the Statistical Office of the General Prosecutor of Albania Republic, about $41.1 \%$ of crimes such as murder, wounding, robbery with violence, kidnapping etc are committed by young people 19-26 years old age group and this percentage is increased a lot during the recent years.

A study of family background of young people who have committed criminal acts with a high level of aggression against another's life shows that most of them are adults grown up and socialized in families where is exercised violence, where older males discuss about perverse behaviours, for crimes and violence against others.

Violence in Albania is a deep-rooted factor in our mentality, as a defensive measure against bad habits. But this is not true at all, because a child or a young man can not be educated by force, as it really can get young people out of troubles", but not as a protective factor but as a fear one. This is a great mistake for every parent; we can say a lack of culture. A violated child is likely to be closed in him, timid and weak in society because it is always used to make what was told or ordered by others. Violence is the ignorance of those who think that it is punishment or education. In this society it is true that there are many risks and for an adolescent it is easy to do mistakes. Parents must stay near with them as well as educate them with communication.

\section{References}

European Commission. (2010). Communication from the Commission to the European Parliament and the Council: Commission Opinion on Albania's application for membership of the European Union 
EU Heads of Mission to Albania. (2010). Local strategy for the implementation of the EU Guidelines on violence against women and girls and combating all forms of discrimination against them [Local strategy for implementing teh advices of EU for the violence against women and girls of all discriminations forms]. Tiranë, Shqipëri.

INSTAT. (2009). Health Demographic survey. Tirana, Albania.

INSTAT. (2009). Violence within family in Albania - National Survey. Tirana, Albania.

National Assembly. (2010a). Rezolution "fighting the violence towards women and the increase of National Assemblyary dimension of the fight against violence within family". Tirana, Albania.

National Assembly. (2010b). Law No. 10329 date 30.9.2010 "For some additions and changes in the Law No. 9669, Date 18.12.2006 "For actions toward against violance in family relationship", revised. Tirana, Albania.

National Assembly. (2010c). Law No 10221, date 04.02.2010 "For protection because of discrimination". Official Bulletin, No. 15, Page 482. Tirana, Albania: The center of official publication.

National Assembly. (2008). Law No 9970, date 24.7.2008 "For gender equality in the society". Official Bulletin, No. 125, Page 5540. Tirana, Albania: The center of official publication.

National Assembly. (2006). Law No 9669, date 18.12.2006 "For actions against violence in familiar relationship". Official Bulletin, No. 150, Page 6113. Tirana, Albania: The center of official publication.

Ministry of Labour and Social Affairs Services of Albania. (2010). Guidance of Ministry of Labour and Social Affairs Services No.1220, date 27.5.2010 For the determination of monitoring and evaluation indicators of gender equality and violence against women, including violence within family, their monitoring, and collection and processing. Official bulletin of the Republic of Albania, 78 . Tirana, Albania: The center of official publication.

Ministry of Labour and Social Affairs Services of Albania. (2010). Annual Monitoring Report for SKBGJ-DHF 2007-2010, JanuaryDecember 2009. Tirana, Albania.

UN Security Council Resolution 1325 (2000). [On women, peace and security]. 
